\title{
Contribution of EPMA to airborne pollen analysis
}

\author{
F Guimarães ${ }^{1}$ L Duque ${ }^{2}$, H Ribeiro ${ }^{2}$, R Sousa ${ }^{2}$, I Abreu ${ }^{2,3}$ \\ ${ }^{1}$ National Laboratory of Energy and Geology, S. Mamede Infesta, Portugal \\ ${ }^{2}$ Environment and Society Group, Geology Centre of the University of Porto, \\ Portugal \\ ${ }^{3}$ Biology Department of Faculty of Sciences of the University of Porto, Portugal \\ E-mail: fernanda.guimaraes@lneg.pt
}

\begin{abstract}
As a component of aerosol, pollen is found in suspension with other mineralogical and anthropogenic particles that can adhere to the pollen wall. The aim of this study was to determine possible alterations that pollen grains suffer under different meteorological conditions in the coastal city of Porto, Portugal. For this study, 2 airborne pollen types were taken into account: Poaceae and Alnus spp sampled in July 2010 and February 2011, respectively. Quantitative analysis and X-ray map analysis were performed with a Field Emission Electron Probe Microanalyser (EPMA). Samples were mounted over adhesive carbon tape and carbon coated. Control pollen showed mainly the presence of $\mathrm{C}, \mathrm{O}, \mathrm{N}, \mathrm{P}, \mathrm{K}$, $\mathrm{Mg}, \mathrm{S}, \mathrm{Cl}$ and $\mathrm{Ca}$ in different quantities, depending on the considered species. Airborne pollen consistently revealed a higher content of $\mathrm{Mg}$ and $\mathrm{Cl}$ than control pollen, while $\mathrm{Si}, \mathrm{Ca}$, $\mathrm{K}$ and $\mathrm{P}$ contents varied differently according to the samples. Our results show that during their "flight", pollen grains acquire an external coating, become heavier and change significantly their composition.
\end{abstract}

\section{Introduction}

Aerosol is a combination of liquid droplets and small solid particles, suspended in a gas or a mixture of gases. Particles from aerosol, also called particulate matter, have different sources, sizes and compositions. Sea-salt, mineral dust, particles derived from carbonaceous combustion and biological particles (e.g. pollen grains) are some examples of particles that make up atmospheric aerosol [1].

Types, sources, chemical composition and size range are the variables commonly studied by works that focus particulate matter $[1,2]$. Among these studies some draw attention to the study of biological airborne material namely pollen.

The pollen grain is the male gametophyte of seed plants, being part of the sexual reproduction cycle. They are biological particles that can be dispersed by wind along several kilometres and consequently can be found in suspension in the atmosphere with natural and anthropogenic pollutants. Pollen grains are a seasonal air pollutant and their presence and amount in the atmosphere depends on a wide range of factors including meteorological (temperature, rain, humidity, wind, etc), biological (physiological state of plants, plants distribution, etc) and topographical issues.

Several techniques, such as SEM-EDS [3, 4] and Raman spectroscopy [5, 6], have been employed to characterize pollen wall composition as well as adhered particles. Also, EPMA was used by Cerceau-Larrival et al $[7,8]$ to characterize pollen and study the influence of pollution on its composition. Presently, no X-ray quantitative microanalysis study has been performed on pollen directly sampled from the atmosphere.

The aim of this study was to determine possible alterations that pollen grains suffer under different meteorological conditions in the coastal city of Porto, Portugal, using EPMA. 


\section{Methods}

This study was conducted in Porto which is the second largest city of Portugal. This city is limited on the west by the Atlantic Ocean and on the south by the Douro River. The annual average temperature is around $15^{\circ} \mathrm{C}$, annual air humidity is between $75 \%$ and $80 \%$, and the total annual mean precipitation varies between $1000 \mathrm{~mm}$ and $1200 \mathrm{~mm}$. Prevailing winds are from the $\mathrm{W}$ and NW in summer and from the E and SE in winter $[9,10]$.

Airborne pollen sampling was performed using a 7-day volumetric spore trap (Burkard Co. Limited) set on the roof of the Faculty of Sciences in Porto. This sampler is composed by a built-in vacuum pump that allows air sampling at 10 litres per minute (simulates human inhalation) and has a $2 \times 14 \mathrm{~mm}$ intake orifice through which the sampled particles are impacted on a double-sided carbon tape supported on a clockwork-driven drum (rotating once every 7 days). A vane tail keeps the intake orifice facing the wind. After exposure the tape was cut into daily segments and mounted on slides.

Control pollen samples were collected in public gardens or sidewalks. In the laboratory, anthers were separated from extraneous materials, dried at $27^{\circ} \mathrm{C}$, gently crushed and the pollen thus released was passed through different grades of sieves and preserved at $-20^{\circ} \mathrm{C}$.

For this study, two airborne pollen types were taken into account: Poaceae and Alnus spp, sampled in July 2010 and February 2011, respectively. Different atmospheric conditions were observed in these two days (table 1). The $6^{\text {th }}$ of July was much hotter and less humid than the $3^{\text {rd }}$ of February. Wind speed was higher on the $6^{\text {th }}$ of July and wind direction was also different in the two days.

Table 1. Atmospheric conditions on the sampling dates.

\begin{tabular}{|c|c|c|c|c|}
\hline & $\begin{array}{c}\text { Temperature } \\
\left({ }^{\circ} \mathrm{C}\right)\end{array}$ & $\begin{array}{c}\text { Relative } \\
\text { humidity }(\%)\end{array}$ & $\begin{array}{c}\text { Wind speed } \\
(\mathrm{m} / \mathrm{s})\end{array}$ & $\begin{array}{c}\text { Wind } \\
\text { direction }\end{array}$ \\
\hline & \multicolumn{2}{|c|}{ Average } & Maximum & \\
\hline 6 Jul 2010 & 28.83 & 47.52 & 7.03 & $W-N-E$ \\
\hline 3 Feb 2011 & 10.28 & 73.34 & 5.83 & $N-E$ \\
\hline
\end{tabular}

Qualitative, quantitative and Intensity X-ray map analyses were performed with a Field Emission Electron Probe Microanalyser (EPMA) JEOL JXA-8500F. To maintain similar conditions of analysis, control pollen was also mounted over adhesive carbon tape and carbon coated. Carbon coating thickness was kept constant in all samples. Since analyzed pollen size ranges between 20 and $30 \mu \mathrm{m}$, EDS qualitative analyses were performed at $10 \mathrm{kV}$ and WDS quantitative analyses and X-ray dot-maps were performed at $6 \mathrm{kV}$. These accelerating voltages ensure that the volume of excitation caused by the beam is smaller than pollen size. It is accepted a density of 1 for biological material [11]. In this work we tried to avoid the irradiation of external particles adhered to the pollen wall in order to focus on the pollen itself.

\section{Results}

We started by acquiring EDS spectra for both control and airborne pollen. Figure 1 compares an example of airborne Poaceae pollen spectrum to an example of control Poaceae pollen. Figure 2 compares an example of control Alnus pollen with airborne Alnus pollen. Control pollen showed mainly the presence of $\mathrm{C}, \mathrm{O}, \mathrm{N}, \mathrm{P}, \mathrm{K}, \mathrm{Mg}, \mathrm{S}, \mathrm{Cl}$ and $\mathrm{Ca}$ in different quantities, depending on the considered species. There are differences in composition between control and airborne pollen. The most evident of those differences is an increase in $\mathrm{Mg}$ and $\mathrm{Cl}$ contents, in both pollen types, and an increase in $\mathrm{Na}$ and $\mathrm{Al}$ in Alnus airborne. 


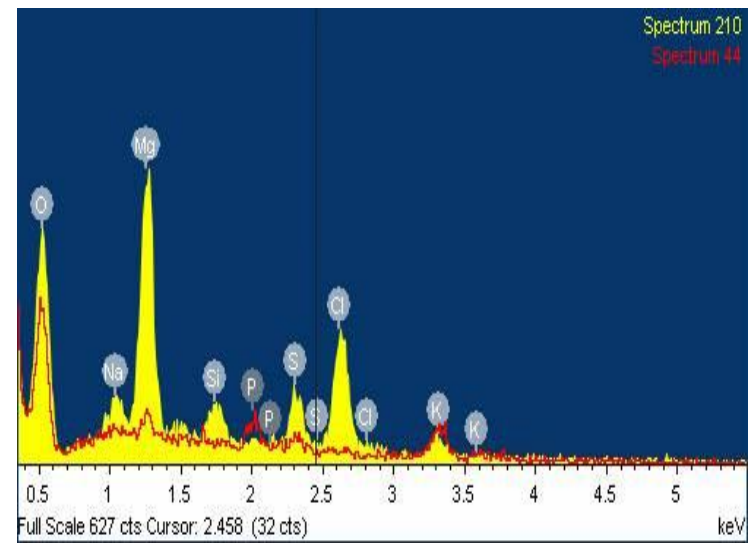

Figure 1. EDS spectra of airborne (yellow) and control (red) Poaceae pollen.

Beam conditions: $10 \mathrm{kV}, 10 \mathrm{nA}$.

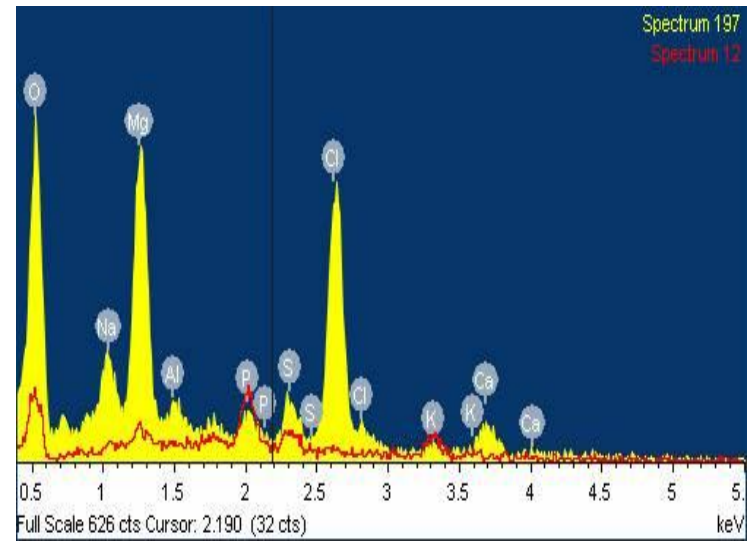

Figure 2. EDS spectra of airborne (yellow) and control (red) Alnus pollen.

Beam conditions: $10 \mathrm{kV}, 10 \mathrm{nA}$.

It was also possible to perform subsequent WDS quantitative analyses to a set of pollen grains, which allowed us to confirm these alterations (figures 3 and 4). Airborne pollen consistently revealed a higher content of $\mathrm{Mg}, \mathrm{Cl}$ and $\mathrm{O}$ than control pollen, while $\mathrm{K}$ and $\mathrm{N}$ contents varied differently according to the pollen type.

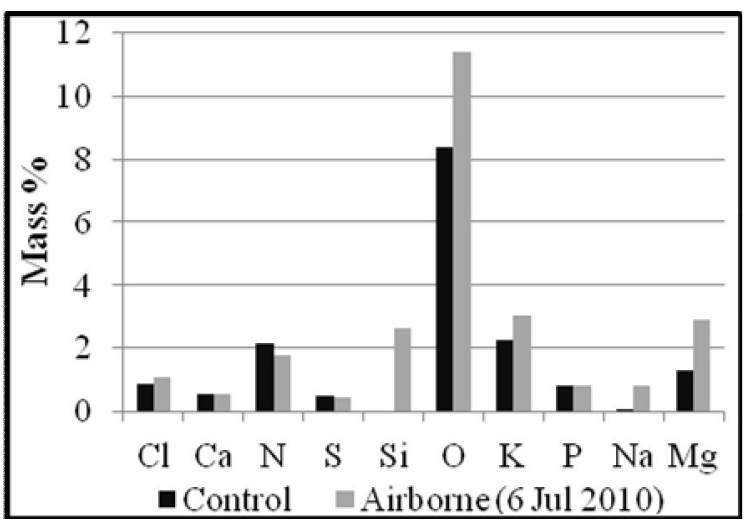

Figure 3. Mass \% of analyzed elements of airborne and control Poaceae pollen. Results represent an average of 13 analyses. Beam conditions: $6 \mathrm{kV}, 15 \mathrm{nA}$.

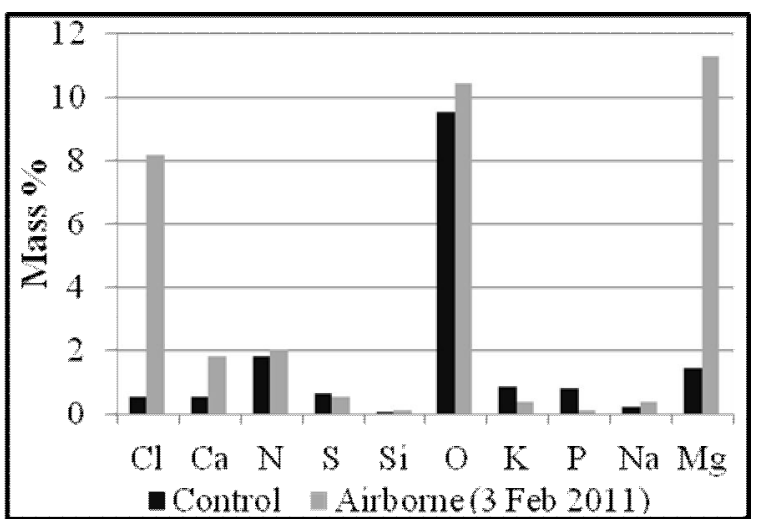

Figure 4. Mass \% of analyzed elements of airborne and control Alnus pollen. Results represent an average of 15 analyses.

Beam conditions: $6 \mathrm{kV}, 15 \mathrm{nA}$.

There was a small amount of Si in control Alnus pollen whereas in control Poaceae pollen Si was not detected. A great increase in Si content was observed in airborne Poaceae pollen collected on the $6^{\text {th }}$ of July, while no such increase was observed in airborne Alnus pollen sampled on the $3^{\text {rd }}$ of February. On the other hand, in Poaceae pollen the $\mathrm{Ca}$ and $\mathrm{P}$ contents remained similar between control and airborne samples, whereas in airborne Alnus pollen an increment in $\mathrm{Ca}$ content and a decrease in $\mathrm{P}$ content was observed.

Finally, it was possible to perform X-ray dot maps for $\mathrm{Mg}, \mathrm{Cl}, \mathrm{Ca}$ and $\mathrm{Si}$, elements chosen because they had shown the greatest differences in the overall of the quantitative analyses. These maps allowed comparing the changes in the elemental distribution between control and airborne pollen. Maps are presented for just one pair (control/airborne) of each pollen type in figures 5 and 6 . One may observe the different mass compositions of the pollen wall and also some attached and surrounding particles. An increase in the $\mathrm{Mg}$ and $\mathrm{Cl}$ content was observed on the pollen wall of both 
Poaceae and Alnus. Particles around the pollen grains also have a great amount of these elements in their composition. Si is not a component of Poaceae pollen but can be seen on the airborne pollen wall and on the particles nearby. On the other hand $\mathrm{Ca}$ is a component of Poaceae pollen wall and in this case it seems masked by other elements. The opposite situation occurs for Alnus pollen in what $\mathrm{Si}$ and $\mathrm{Ca}$ are concerned: there is an increase in Ca content while intrinsic Si appears to be concealed.
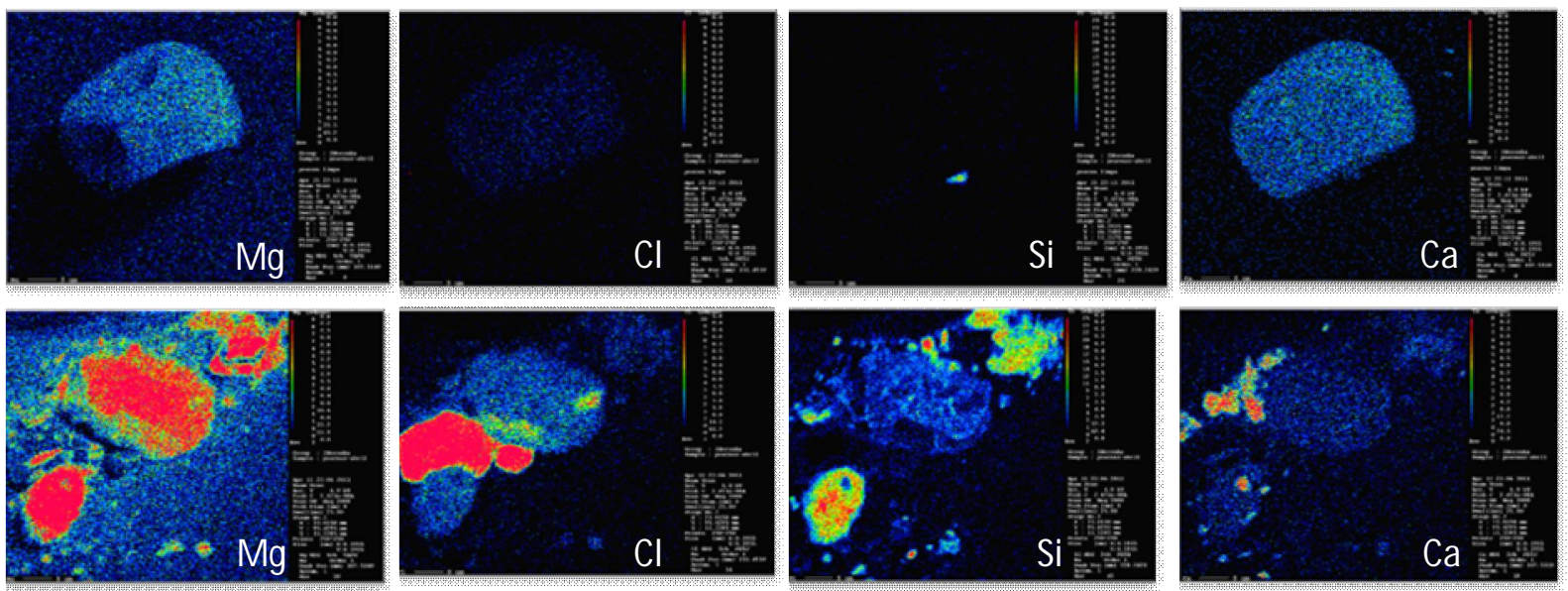

Figure 5. Intensity X-ray dot maps of control (above) and airborne (below) Poaceae pollen. Beam conditions: $6 \mathrm{kV}, 25 \mathrm{nA}$.
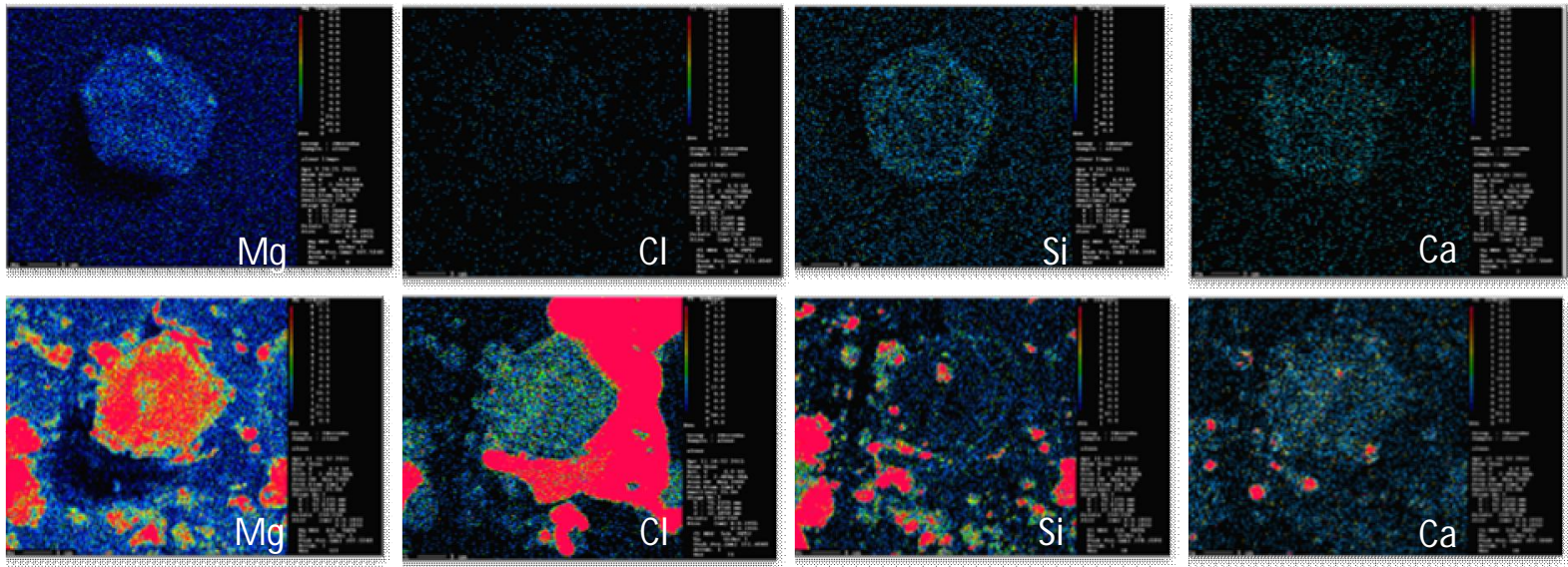

Figure 6. Intensity X-ray dot maps of control (above) and airborne (below) Alnus spp. pollen. Beam conditions: $6 \mathrm{kV}, 25 \mathrm{nA}$.

\section{Discussion}

EPMA allowed us to analyze and to compare pollen grains in order to understand what happens during their travel through the air of Porto. EPMA is a technique used for the study of biological materials with several described difficulties [12]. The use of low energy beam conditions minimizes damage of the samples under the impact of the electron beam. In this case an accelerating voltage of $6 \mathrm{kV}$ ensures that the volume of excitation is significantly smaller than the samples. The simultaneous analysis of control and airborne pollen allowed us to minimize the errors that might have been done due to the fact that the electron beam and the pollen surface aren't always perpendicular are consistent in both samples and so they are comparable. 
Among the major constituents of the pollen wall are $\mathrm{C}, \mathrm{O}, \mathrm{N}, \mathrm{P}, \mathrm{K}, \mathrm{Mg}, \mathrm{S}, \mathrm{Cl}$ and $\mathrm{Ca}$. The N, P and $\mathrm{K}$ (together with $\mathrm{C}, \mathrm{H}$ and $\mathrm{O}$ ) are the main constituents of organic matter. Also, on airborne pollen was observed a major presence of other elements such as $\mathrm{Na}, \mathrm{Al}$ and $\mathrm{Si}$. Airborne pollen grains seem to acquire an external layer that in some cases covers the surface completely and therefore, in our analysis some elements present on the pollen can be virtually reduced or occulted. Cerceau-Larrival et al [8] call it an "inversion" (when elements change order of dominance) or a "decrease in the number of elements" (when certain elements that appeared on the analyses of freshly shed pollen do not appear in polluted pollen). In this work, pollen may also have acquired an external layer, hiding some elements and changing their order of dominance.

In our study, the external layer is composed mainly of $\mathrm{Mg}, \mathrm{Cl}$ and $\mathrm{Si}$ or $\mathrm{Ca}$ depending on the pollen species considered. This airborne pollen coating seems to be related to sea spray (mainly in Winter), due to Porto's location, since $\mathrm{Mg}^{2+}, \mathrm{Cl}^{-}, \mathrm{Na}^{+}$and $\mathrm{SO}^{2-}$ represent about $95 \%$ of sea water salinity. It can also be related to resuspension or long-distance transport of crustal components ( $\mathrm{Si}$, $\mathrm{Ca}$ and other) [1]. Niemi et al. [13] reported that in samples collected between the English Channel and Antarctica, the amount of $\mathrm{Mg}$-sulphate found in aerosols of the marine boundary layer is the greatest near the coast of Portugal. This can explain the large amount of $\mathrm{Mg}$ found on our samples.

The different alterations of composition observed on the two pollen types can be associated to differences in meteorological conditions (table 1), since samples were gathered in different dates and, in this case, different seasons (Summer and Winter). Pollution may also have an effect on these alterations. The way the substances adhere to or react with the surface of the pollen may also be related to its wall ornamentation, but in this case this does not seem a suitable explanation to the differences observed, because Poaceae and Alnus pollen have similar wall ornamentations (scabrate exine). A follow-up of this study is currently being carried out to confirm our hypotheses.

\section{Conclusion}

EPMA is a reliable method for the identification of pollen grain major elements as well as the adsorbed material to airborne pollen.

Our results showed that during its "flight", pollen acquires an external coating, becoming heavier, and its wall composition is significantly changed. $\mathrm{Mg}$ and $\mathrm{Cl}$ are the main components of this coating. Weather conditions are important to the extent of these modifications.

\section{Acknowledgments}

This work was supported by FEDER funds through the Operational Program Competitiveness Factors - COMPETE and National Funds through FCT - Foundation for Science and Technology in the project $\operatorname{Ref}^{\mathrm{a}}$ PTDC/AAC-AMB/102796/2008 and POCI 2010. Third author benefits from a scholarship (SFRH/BDP/43604/2008) financed by QREN-POPH and FCT.

\section{References}

[1] Giere R and Querol X 2010 Elements 6 215-22

[2] Grobety B, Giere R, Dietze V and Stille P 2010 Elements 6 229-34

[3] Majd A, Chehregani A, Moin M, Gholami M, Kohno S, Nabe T and Shariatzade M A 2004 Aerobiologia 20 111-8

[4] Shahali Y and et al. 2009 Journal of Physics: Conference Series 151012027

[5] Laucks M L, Roll G, Schweiger G and Davis E J 2000 Journal of Aerosol Science 31 307-19

[6] Schulte F, Lingott J, Panne U and Kneipp J 2008 Analytical Chemistry 80 9551-6

[7] Cerceau-Larrival M T, Cauneau-Pigot A, Bocquel C, Carbonnier-Jarreau M C, Derouet L and Verhille A M 1994 Journal of Trace and Microprobe Techniques 12 37-50

[8] Cerceau-Larrival M T, Nilsson S, Cauneau-Pigot A, Berggren B, Derouet L, Verhille A M and Carbonnier-Jarreau M C 1991 Grana 30 532-45

[9] Monteiro A 1997 O clima urbano do Porto: contribuição para a definição das estratégias de planeamento e ordenamento do território (Lisbon: Fundação Calouste Gulbenkian ) 
[10] Santos F D, Forbes K and Moita R 2002 Climate change in Portugal: scenarios, impacts and adaptation measures (Lisbon: Gradiva)

[11] van Hout R and Katz J 2004 Journal of Aerosol Science 35 1369-84

[12] Heinrich K F J 1981 Electron beam X-ray microanalysis (New York: Van Nostrand Reinhold Company)

[13] Niemi J V, Tervahattu H, Virkkula A, Hillamo R, Teinila K, Koponen I K and Kulmala M 2005 Atmos. Res. 75 301-21 